\title{
REPAIRING TALES FROM JAPAN: CHANGES OVER TIME IN PERSONAL NARRATIVES
}

\author{
TIMOTHY J. RINEY \\ International Christian University \\ riney@icu.ac.jp
}

\begin{abstract}
At two different times, Time 1 and Time 2, 13 participants in Japan (8 Japanese and 5 Americans) were asked to spontaneously respond in English to this prompt: "Tell me about one of the most exciting or dangerous moments in your life." The Japanese responded during their first and fourth years of college, which involved an interval of 42 months. The Americans were native speakers of English and responded earlier and later in their one year study abroad program in Japanese language and culture. Three questions addressed by this paper were the following: (a) What types of topics and narrative structures characterize these 26 stories? (b) What types of speaker-initiated repairs appear, and are the repairs the same or different at Time 1 and Time 2? (c) How are the repairs related to different listener (American, Japanese, Filipino, and Taiwanese) assessments of the intelligibility of the narratives?
\end{abstract}

Keywords: Japanese, pragmatics, personal narrative, repairs, intelligibility

\section{Introduction}

The general topic of this paper concerns development in the intelligibility of English as a second language over time and among different types of speakers and listeners. The focus of the paper is on only one small possible contributor to that intelligibility, speaker-initiated repairs in the genre of the "personal narrative."

The paper draws its material from recorded narratives (sometimes called "stories" below) collected from 13 participants. The 13 participants, below referred to as "speakers," were all university students in Japan. They each did four tasks in the medium of English at two points in time. Three of the tasks involved reading a word list, a sentence list, and a paragraph. A fourth task, the one used for this paper, had the speakers spontaneously respond to this prompt: "Tell me about one of the most dangerous or exciting moments of your life" in a manner that was somewhat similar to what Labov and Waletsky (1967) and Holmes (1998) had done in order to elicit their respective narratives.

All 13 participants, 8 Japanese and 5 Americans, did the tasks individually in the same room of the same university in Japan and under identical conditions, except with regard to the variable of time. The Japanese speakers did the four tasks the first time, Time 1, when they were about 18 years old and during their first year of college, and the second time, Time 2, about 42 months later during their fourth year. The American 
speakers, all study abroad students about 21 years old and from California, served as a comparison group, and did Time 1 earlier and Time 2 later within the same academic year.

Analysis of the speech material gathered from the first three tasks, the reading of words, sentences, and a paragraph, has focused on how selected aspects of the English speech of some of the Japanese students changed over time in ways that the speech of the American comparison group did not. Previous investigations of this speech (most of which are listed in the references to Riney, Takagi and Inutsuka 2005) have covered a range of topics, including the following: native or foreign accent, intonation, liquids, connected speech phenomena, voice onset time, and the relationship between two or more of these phenomena, sometimes with reference to a certain theory of language or language learning, or a pedagogical proposal related to language education. Some of the findings of these previous studies were based on acoustic measurements. Others were based on naïve American and naïve Japanese listener judgments, and still others were based on judgments of listeners trained in phonetics.

Although the speech material gathered from the first three tasks, the reading tasks, has been investigated several times and from multiple points of view, nothing in the way of pragmatics has ever been done with the most interesting but open-ended and challenging fourth task, involving the personal narratives. This paper describes a first attempt to approach these personal narratives from a pragmatic point of view, and one that also considers the "intelligibility" of the narratives.

Based in part on Munro (2008), intelligibility in this paper refers to two types of assessments made by listener-raters (or "listeners"). One is each listener's self-reported and estimated degree of recognition of the words of the speaker. The other is the listener's self-reported and estimated degree of understanding of the overall intended meaning of the speaker. Because the interest here is in international and cross-cultural settings, the intelligibility of both groups of speakers, American and Japanese, were all based on assessments by four separate groups of listeners: 3 Americans, 4 Japanese, 6 Filipino, and 8 Taiwanese. (These listener assessments are part of a separate and ongoing study that is being prepared for a separate paper that has no pragmatic focus.)

With the above considerations in mind, this paper will briefly address the following three questions: (a) What are the topics and structures of the narratives? (b) What type of self-initiated repairs occur, and to what extent are they the same or different at Time 1 and Time 2? (c) To what degree do repairs appear to be related to different listener assessments of the intelligibility of the narratives?

We will begin by addressing the first question below.

\section{Narrative topics and structures}

In response to the prompt, "Tell me about one of the most exciting or dangerous moments of your life," a number of the narratives involved one or more of the following topics: (a) an event that happened during childhood, (b) an event that happened when one was away from one's hometown or native country, (c) an event that involved a personal or professional challenge or development, and (d) a really dangerous moment. 
The topics of the 26 stories (13 speakers x 2 times) are listed below. Numbers 1 to 5 refer to the American speakers and their 10 stories. Numbers 6 through 13 do the same for the 8 Japanese speakers and their 16 stories. After each speaker's gender is identified, the first topic listed refers to the Time 1 story and the second topic to the Time 2 story.

1. Female: Being caught underage in a Las Vegas casino. When a child, getting lost in drive-in movie theater.

2. Female: When a child, canoeing with my family in Canada. Defending myself against men on a street in San Francisco.

3. Male: Applying for a career-track summer internship. First time bungee jumping.

4. Male: Losing a high school girlfriend at a UCLA fraternity party. An encounter with gangsters with guns in L.A.

5. Female: The first night in Bangkok. My summer internship in Washington, D.C.

6. Female: As a child, experiencing nature in Scotland. Learning among Lakota Indians what it means to be Japanese.

7. Female: As a child, almost drowning. Dealing with a man in a carpet shop in Istanbul.

8. Female: Shocked in Manila by the difference between the rich and the poor. A taxi ride in the wrong part of New York City.

9. Female: As a child, caught in a sudden and severe thunderstorm. Proving myself in English at a United Nations student conference.

10. Female: Winning an award in high school. Dealing with men in carpet shops in Istanbul (similar to 7 above).

11. Female: Going to Mexico to study Spanish. An struggle with a pickpocket in Bulgaria.

12. Male: As a child, accidentally starting a fire. (This speaker had the same topic at Time 1 and Time 2.)

13. Female: As a child, walking around Harlem, New York, with my father. Visiting the Cannes Film festival in France.

The narrative structures of the 26 stories were examined using part of the framework of Labov and Waletsky (1967), a framework that is somewhat dated but which continues to be cited and has been used with reference to narratives produced by cultures outside of North America (e.g., Holmes 1998). (For a critical view of Labov and Waletsky 1967, see Schegloff 1997).

Labov and Waletsky (1967) analyzed narratives produced by speakers who were responding to a prompt asking them to describe a time when they had been "almost killed." Based on the personal narratives that they gathered in the U.S., Labov and Waletsky noted that the following components appeared in a number of the narratives: abstract, orientation, complicating action, resolution, conclusion, and coda.

Unfortunately, unlike the U.S., Japan is a generally safe country, where it is difficult to get "almost killed." For this reason, for the current study, the 13 speakers, including the 8 Japanese, were given the following "safer" prompt: "Tell me about one of the most dangerous or exciting moments in your life."

As expected, and as Holmes (1998) also found, some but not all of the narratives produced by the 13 speakers in the current study had all of the six structures noted by 
Labov and Waletsky (1967). One narrative that did have all six structures was the Time 2 narrative of Speaker 2, an American female. Her narrative will now be briefly paraphrased in a way that will illustrate the function of each of the six structures of Labov and Waletsky (1967).

Abstract: OK, I'll tell you about the time I was assaulted.

Orientation: It was one night last year, in San Francisco, my sister and I were returning to a hotel about 10 o'clock at night. The street was deserted.

Complicating Action: Suddenly four men step out from a side street in front of us. My sister and I cross over to the other side of the street, and seconds later the men do the same. Two of them approached and grabbed us.

Resolution: Well, it all happened so quickly. My sister and I both had had a lot of training in karate. A lot of training. We were able to kick the men in their sensitive spots and run away before they could recover and catch us.

Conclusion: We got away safe. We were not hurt.

Coda: That was my dangerous moment.

Below we will refer to this story set in San Francisco as the "Assault Story." Continuing to consider narrative structures, we will now consider both the Time 1 and Time 2 narratives of the same Japanese female speaker, Speaker 6, beginning with her Time 1 story. (Italics represent the voice of the Interviewer.)

I'd like to speech um my experience, mmm, in going to Scotland when I, I was at 12, 12 years old my family traveled to Scotland and we met uh one person who is vegetarian mhm so, um she took me, uh, she took us to a little gulf, a little bay, um surrounded um cliff, $\mathrm{mhm}$ and small shore Yes. $\mathrm{mhm}$ so I feel I felt in there, very, very, [Japanese pause filler] I have very good experience there um because there is no one but us and there is no living thing but only sh [???] only wave, uh, only rip [ripple?] coming up to us and sky, sky's color is um dark blue $\mathrm{mhm}$ and there is many little stone $\mathrm{mhm}$ and this color is blue and white and pearl silver, and pink, yellow, very, very variety $m \mathrm{hm}$ and and I moved I was moved very much, and $\mathrm{mmm}$, that scene is um never I can never forget that scene . . because I haven't ever seen that beautiful thing, so my um special experience is this. Okay, thank you very much. [2 min, $11 \mathrm{sec}$; about 155 words]

Speaker 6's story at Time 1 above, told during the beginning of her first year of college, is referred to below as "the Scotland story." This Scotland story is simply a description of her family trip to a Scottish cove and her appreciation of the beautiful nature there. As for narrative structures, the story has a clear abstract (the first sentence) and coda (the last sentence), but it does not have any complicating action or resolution, which are probably less likely to appear in a story that involves a continuous state of "excitement," rather than a sudden "danger," such as in the Assault story above.

Now we will consider the story that Japanese Speaker 6 told 42 months later at Time 2 , during her fourth year of college. Between Time 1 and Time 2, she had spent about nine months in a study abroad program at a university in California, and her "most dangerous or exciting event" occurred there. Her story begins with a description of a fight that she observed between "full blood" and "mixed blood" Lakota males about who is a "real Indian." She then confesses her difficulty in deciding what role she should have in the conflict. Without resolving that, she moves on to explain how the Indians' struggle 
for identity in modern urban California, burdened by the knowledge of their heritage, is similar to her own struggle with her Japanese heritage and identity. We will refer to this Time 2 story, which follows, as the Identity Story. (In order to save space, the $\mathrm{mhm}$ of the Interviewer shown in the Scotland Story above is not shown in the Identity Story below.)

The one night, I was at [???] University [in California], it was two years, college, and there is only native American students, maybe some white student and Chicano student, and I was the only Japanese student out there. And one night there is a fighting heh and I was there because of my Lakota language class and after class is finished I went outside and some guys are fighting and we really don't know what to do but because they are all drunk and they were heh totally stoned heh so, because I'm like, I think the reason why they got fight was because of the difference of blood quantity. But because one guy was full blood and the other one was not, he was mixed. And this full blood guy he wanted to tell him, I think he wasn't sure, or he maybe he felt insecure so he wanted to fight this mixed blood person and to say just he is not Indian, he is not the same. And it was really intense because many students are afraid, they know these tensions but on the surface people think, people thought at [???] U. there is a tension between Chicano students and native American students. It wasn't true. Actually there is a tense between the mixed blood students and the full blood and no matter how much blood you have [it?] depend on how you look, color tone of the skin or the your accent speeches and these stuff or what kind of clothes you wear. And so after that we had a meeting, a student meeting and many people told their own stories on how to improve situations. Right. And we just addressed all issues. Not only racism, but the curriculums, or the teachers' programs, or the governmental policies. Everything. And unfortunately many teachers say they didn't want to be involved in this kind of situation. They are more just hired, part-time teachers. But the some old teachers who founded this university they got involved, we had really good time. But it was exciting and dangerous for me because I wasn't sure what kind of position I can take, or what kind of stance I could take. But I wanted to say something but I was uh afraid of being misunderstood, and also I didn't wanna invade . . cause I remember the first week I went to there, one of my friends, he he became my friend later but he was really aggressive to me first and he was Lakota student and I was taking Lakota language class and he came to me and he said "Why you taking Lakota language class? It's my language, its not your language!" You know? And he said this university is made for native people and Chicanos. Not for outsiders and he mentioned about anthropology student or linguistics student who came there and just left without communication or understanding and, so, I . . I think at least 3 or 4 times I tried to stop but I wanted to continue and I wanted to make friends, there with just to communicate with them and talk about how they feel about their identify and I wanted to compare with my fear of my identity. Yeah cause I actually I escaped from Japan, I went to United States just to get away from everything here [Japan]. I wasn't sure who I am and I wanted to know, and so, maybe I think this fear made me connect with this student, because I didn't know why I'm Japanese. People always ask me Where you from? Who you are? Who are you? You know. And I always say, I'm Japanese. But I wasn't proud enough to address my heritage, or I wasn't sure why I can say I am Japanese. Cause when I compare my gener-my parents' generation, my grandparents generation with my generation, we are totally different and I don't know why I can still say I am Japanese. I 
don't know what makes me as Japanese and I thought it is similar to those young native kids who grown up in urban cities yeah, you know. Thank you very much. [4 min, 52 sec; about 685 words]

Japanese Speaker 6 is much more fluent in her Identity Story at Time 2 than in her Scotland Story at Time 1. The Identity Story takes twice as much time to tell but produces over four times the number of words. In terms of narrative structure, whereas the Scotland Story has a explicit abstract and coda, the Identity Story has neither. In addition, whereas the Scotland story had no complicating action, the Identity Story arguably has three complicating actions: the Lakota males' full blood vs half blood fight, the you can't study my language directive from the Lakota male to the Japanese female speaker, and the same speaker's struggle for her Japanese identity. None of these three complicating actions gets neatly resolved or has a resolution as clear as that of that of the Assault Story. The Identity Story also lacks a clear conclusion and coda. It is unknown to what extent these differences in narrative structure could affect the word recognition and overall understanding of different listeners.

\section{Repairs and changes between Time 1 and Time 2}

"Repairs" here refer to how a speaker deals with some misunderstanding or potential misunderstanding. In a personal narrative, where one person does most of the talking, we are especially interested in speaker-initiated repairs of their own speech. We will begin by considering the repairs in the Time 1 Scotland Story.

The Scotland story produced only one short paragraph of typescript, yet it has seven repetitions or repairs of various types, shown below:

\section{I, I}

twelve, twelve

she took me, us, she took us

a little gulf, a little bay

but only wave, uh only rip [probably "ripple"]

I moved, I was moved

That scene is, um, never I can forget that scene

The short Scotland Story is dense with repairs and repetitions involving pronunciation, grammar, and vocabulary. Some of these involve primarily form ("I moved, I was moved") and others truth ("she took me, us, she took us").

Although the Identity Story has four times as many words, it has fewer repetitions and repairs than the Scotland Story, and what repetitions and repairs there are appear to be primarily concerned, not with form, but with meaning, as in "I wasn't sure what type of position I should take or what type of stance I should take." Although Japanese Speaker 6 is probably capable of repairing much of her Time 2 grammar, she is also probably so wrapped up in her content that she is no longer interested in correcting segments such as "and one night there is a fighting" and "the reason they got fight was."

It is possible that Japanese Speaker 6's increase in fluency is in part due to a possible concurrent decrease in any desire to take the time to check her grammar as she speaks. 
At Time 2 she sounds much more interested in the truth about what happened in her Identity Story.

Japanese Speaker 6's language has changed in other ways that might be briefly mentioned. In Time 1 she used a Japanese pause filler; in Time 2, she uses pause fillers such as like and you know, also used by the American speaker comparison group.

We will now consider the Japanese group of eight speakers as a whole and changes between Time 1 and Time 2. In order to do this we need to divide the Japanese into two sub-groups: The first sub-group is comprised of the four Japanese, including Speaker 6, who had studied abroad for nine months or more between Time 1 and Time 2. The second group is the remaining four Japanese who did so for six weeks or less. Henceforth, we will refer to these two sub-groups as the 9-month group and the 6-week group, respectively.

The 9-month group had studied abroad for 9 months or more at universities in California, Mexico, and the Netherlands. By Time 2, their English, based on assessments done with the three reading tasks (word, sentence, and paragraph) mentioned earlier, had changed measurably in one or more ways (e.g., involving accent, suprasegmentals, liquids, or voice onset time).

As happened in the Time 2 narrative of Japanese Speaker 6, the Time 2 narratives of the other speakers of the 9-month group tended to be told more fluently. Additionally, they took more time to tell, and they involved more words, and complexity in general. With regard to the 9-month group's speakers' initiated repairs, another difference observed at Time 2 was that they were making fewer repairs per paragraph or per minute, and the repairs that they were making were more likely to involve content and truth rather than form and grammar. In other words, the 9-month group, which had generally been like Speaker 6 at Time 1, returned to Japan at Time 2 changed in ways similar to the ways that Speaker 6 had changed.

At both Time 1 and Time 2, on the other hand, the 6-week group was more like Speaker 6 at Time 1 . The 6 -week group thus showed less language change overall between Time 1 and Time 2. This was generally true for the earlier assessments done of the three reading tasks (word, sentence, and paragraph), and it was also true for the fourth task, involving the personal narratives, considered in this paper. At Time 2, the 6week group, like Speaker 6 at Time 1, continued to make relatively more repairs, and the repairs that they did make (compared to the 9-month group at Time 2) were more often about form and grammar than about content and truth.

\section{Repairs and intelligibility}

As was pointed out above, "intelligibility" in this paper is based on two types of listenerrater assessments, one involving word recognition and the other involving understanding a speaker's overall intended meaning. Intelligibility, like accent, is of course dependent on who is talking and who is listening. For the purpose of this paper, the assessments of four groups of listeners were considered. All groups were comprised of university students and the average age of each group was about 20 years old. (The listeners became involved in this study several years after the speakers did, and it is highly unlikely that any of the listeners could have known any of the speakers.) 
Two of the listener groups, one comprised of 3 Americans and one comprised of 4 Japanese, were based in Tokyo and were very similar to the 5 American and 8 Japanese speakers of this study who have already been described. A third listener group, comprised of 6 native speakers of Tagalog or Cebuano, was in Manila and had never been outside the Philippines. A fourth group of 8 Taiwanese, 6 of whom had never been outside of Taiwan, was comprised of 8 native or second language speakers of one or more varieties of Chinese.

These four groups of listener-raters were in three different countries but they all did their ratings of intelligibility in a similar university classroom setting, and in the same way. Immediately after listening to a digital recording of each personal narrative (2 to 3 minutes in length) the listeners had 90 seconds to circle a number indicating the approximate percentage of words that they thought they had recognized in that narrative, and then circle an additional number indicating the approximate percentage of the speaker's overall intended meaning that they thought that they had understood in that same narrative.

This listener-rater study is still ongoing and will eventually involve more types of listener groups, but some of the current general findings that have a bearing on this paper will now be reported. One expected finding is that of the four listener groups, the American listeners reported that they had understood the American speakers the best (about 97 to 100\% averages for both word recognition and overall intended meaning). In this, the Americans were followed by the Filipinos, and then the Taiwanese. The Japanese had the most difficulty understanding the American stories, with the intelligibility ratings varying between 20 and 40 percent, depending on the speaker and story.

As for the intelligibility of the Japanese told stories, the results were quite different. The intelligibility rating of the Japanese stories varied a lot from one speaker to the next, and sometimes from one time (or story) to the next for the same speaker, but the ratings of the Japanese speakers as a group did not vary that much across the four listener groups. Unlike what happened with the American speaker group, no listener group rated the Japanese speakers as being either highly intelligible (e.g. above 90\%) or highly unintelligible (e.g., below 35\%). Furthermore, the Taiwanese and the Filipinos understood the Japanese stories better than the Japanese understood the Americans.

One could probably partially explain some of the findings that have just been reported above, but our main purpose here is to consider the relationship between intelligibility and speaker-initiated repairs. We have seen the repairs in the typescripts of the two stories from Japanese Speaker 6 above. With this in mind, we now turn to this question: Was it the case that speakers who made fewer (or more) repairs tended to sound more (or less) intelligible?

The reader will recall Japanese Speaker 6's Time 1 Scotland Story had a relatively large number of repairs of various types in a short space, and her longer and more fluent Time 2 Identity Story had relatively few repairs, and these repairs were more likely to be about content or meaning than about form or grammar. This type of pattern also appeared among some other stories of the 9-month group. For the 26 stories as a whole, however, did this type of difference in the frequency of repairs appear to be related to stories being rated as more or less intelligible? No it did not. This was regardless of whether intelligibility was based on word recognition or on understanding of overall 
intended meaning. Thus, addressing our third question posed above, one cannot say that the speakers who made the most (or fewest) repairs were the most (or least) intelligible.

\section{Conclusion}

This paper has briefly addressed three questions. In addressing the first question, about narrative topics and structures, it found that Japanese and Americans tended to tell stories about similar topics (childhood, travel, achievement, and danger). In both Japanese and American groups there were some narratives that included all six narrative structures of Labov and Waletsky (1967) and others that did not. Also, in both groups, stories that were about "danger" were more likely to have a complicating action than were stories merely about "excitement." Thus, the Japanese and American groups did not really differ from one another with regard to topic and narrative structure.

With regard to the second question, about change between Time 1 and Time 2, no obvious change appeared in the stories of the American native speaker comparison group, as was expected. Also expected was the finding that the Time 2 stories of those Japanese who spent more time overseas (the 9-month group) tended to be longer and more complex, and told with greater fluency than the same speakers' Time 1 stories.

When this study began it was not known whether the number and type of speaker initiated repairs at Time 1 and at Time 2 would be any different. Thus it was somewhat surprising that the 9-month group made fewer repairs at Time 2 than at Time 1, and, furthermore, their repairs at Time 2 (compared to those at Time 1) were more likely to involve a greater proportion of repairs of content or truth, as opposed to repairs of form or grammar. This type of change was not observed among those Japanese who did not spend as much time abroad between Time 1 and Time 2 (the 6-week group), whose Time 2 repairs were generally similar in type and number to their Time 1 repairs.

Finally, in response to the third question, about repairs and intelligibility, no obvious link appeared between them. In other words, speakers who made more (or fewer) repairs were not found to be more (or less) intelligible. One might expect that a speaker who made the repairs that were necessary for intelligibility, and who made these repairs effectively enough to enhance intelligibility, would end up being more intelligible than other speakers who did not make the needed repairs (at all or effectively), but this study unfortunately was not designed to differentiate "effective" repairs from "ineffective" repairs. Doing so would have taken much more time on the part of the listeners, who would have had to try to assess the effectiveness of each individual repair.

One of the major limitations of the current study was that it did not address of what constitutes effective pronunciation, which is speaker and listener determined, and probably varies across the different speaker-and-listener dyads of this study (e.g., Japanese-Taiwanese, American-Filipino, etc). Pronunciation probably affects word recognition, and one needs to have a minimal level of word recognition in order to obtain any understanding of a repair or of a speaker's overall meaning. Some other important factors not accounted for in this study were language proficiency, speaking rate, lexical difficulty, assumed listener background knowledge, and story complexity and cultural content. This list is not exhaustive. 
Future studies of repairs will have to consider how to begin to account for some of these variables just mentioned. They might begin by investigating repairs that appear in small segments of spoken discourse elicited in a more structured way.

\title{
References
}

Holmes, Janet. 1998. "Narrative structure: Some contrasts between Maori and Pakeha story-telling." Multilingua, 17 (1): 25-57.

Labov, William and Waletsky, Joshua. 1967. "Narrative analysis: Oral versions of personal experience." In Essays on the Verbal and Visual Arts: Proceedings of the 1966 Annual Spring Meeting of the American Ethnological Society, June Helm (ed), 12-44. Seattle, WA: University of Washington Press.

Munro, Murray. 2008. "Foreign accent and speech intelligibility." In Phonology and Second Language Acquisition, Jette G Hansen Edwards and Mary L. Zampini (eds), 193-217. Philadelphia, PA: John Benjamins.

Riney, Timothy J., Takagi, Naoyuki and Inutsuka, Kumiko. 2005. "Phonetic parameters and perceptual judgments of accent in English by American and Japanese listeners." TESOL Quarterly, 39 (3): 441-466.

Schegloff, Emanuel A. 1997. "“Narrative analysis' thirty years later." The Journal of Narrative and Life History 7 (1):1-4.

\begin{abstract}
About the Author
Timothy J. Riney is a Professor in the Department of Language Sciences at International Christian University in Tokyo, where he teaches courses for the Linguistics Major. He has previously published articles in Language Learning, Studies in Second Language Acquisition, Multilingua, and Journal of Multilingual and Multicultural Development.
\end{abstract}

